\title{
Endovascular Therapeutic Hypothermia Adjunctive To Percutaneous Coronary Intervention in Acute Myocardial Infarction: Realistic Simulation as a Game Changer
}

Luis Augusto Palma Dallan ( $\square$ luisdallan@yahoo.com )

UH Cleveland Medical Center

Michael Dae

University of California San Francisco

Natali Schiavo Giannetti

FMUSP: Universidade de Sao Paulo Faculdade de Medicina

Tathiane Facholi Polastri

FMUSP: Universidade de Sao Paulo Faculdade de Medicina

Marian Keiko Frossard Lima

FMUSP: Universidade de Sao Paulo Faculdade de Medicina

Carlos Eduardo Rochitte

FMUSP: Universidade de Sao Paulo Faculdade de Medicina

Ludhmila Abrahao Hajjar

FMUSP: Universidade de Sao Paulo Faculdade de Medicina

Claudia Yanet Bernoche San Martin

FMUSP: Universidade de Sao Paulo Faculdade de Medicina

Felipe Gallego Lima

FMUSP: Universidade de Sao Paulo Faculdade de Medicina

Jose Carlos Nicolau

FMUSP: Universidade de Sao Paulo Faculdade de Medicina

Mucio Tavares de Oliveira

FMUSP: Universidade de Sao Paulo Faculdade de Medicina

Luis Alberto Oliveira Dallan

FMUSP: Universidade de Sao Paulo Faculdade de Medicina

Expedito Eustaquio Ribeiro da Silva

FMUSP: Universidade de Sao Paulo Faculdade de Medicina

Roberto Kalil Filho

FMUSP: Universidade de Sao Paulo Faculdade de Medicina

Pedro Alves Lemos Neto

FMUSP: Universidade de Sao Paulo Faculdade de Medicina 


\section{Sergio Timerman}

FMUSP: Universidade de Sao Paulo Faculdade de Medicina

\section{Original research}

Keywords: therapeutic hypothermia, ST elevation myocardial infarction (STEMI), percutaneous coronary intervention (PCl), acute coronary syndrome (ACS), coronary disease, simulation, training, educational debriefing.

Posted Date: October 4th, 2021

DOl: https://doi.org/10.21203/rs.3.rs-877912/v1

License: (c) (i) This work is licensed under a Creative Commons Attribution 4.0 International License. Read Full License

Version of Record: A version of this preprint was published at Reviews in Cardiovascular Medicine on March 16th, 2022. See the published version at https://doi.org/10.31083/j.rcm2303104. 


\section{Abstract}

Background: Endovascular therapeutic hypothermia (ETH) reduces the damage by ischemia/reperfusion cell syndrome in cardiac arrest and has been studied as an adjuvant therapy to percutaneous coronary intervention (PCI) in ST-elevation myocardial infarction (STEMI). New available advanced technology allows cooling much faster, but there is paucity of resources for training to avoid delays in door-toballoon time (DTB) due to ETH and subsequently coronary reperfusion, which would derail the procedure. The aim of the study was to describe the process for the development of a simulation, training \& educational protocol for the multidisciplinary team to perform optimized ETH as an adjunctive therapy for STEMI.

Methods and Results: We developed an optimized simulation protocol using modern mannequins in different realistic scenarios for the treatment of patients undergoing ETH adjunctive to PCI for STEMIs starting from the emergency room, through the CathLab, and to the intensive care unit (ICU) using the Proteus ${ }^{\circledR}$ Endovascular System. The primary endpoint was door-to-balloon (DTB) time. We successfully trained 361 multidisciplinary professionals in realistic simulation using modern mannequins and sham situations in divisions of the hospital where real patients would be treated. The focus of simulation and training was logistical optimization and educational debriefing with strategies to reduce waste of time in patient's transportation from different departments, and avoiding excessive rewarming during transfer.

Conclusions: Realistic simulation, intensive training and educational debriefing for the multidisciplinary team propitiated feasible endovascular therapeutic hypothermia as an adjuvant therapy to primary $\mathrm{PCl}$ in STEMI. ClinicalTrials.gov: NCT02664194.

\section{Introduction}

Endovascular therapeutic hypothermia (ETH) is performed to reduce ischemia/reperfusion cell syndrome damage in cardiac arrests, ${ }^{1}$ however its role in ST-segment elevation myocardial infarction (STEMI) patients still remains controversial. ${ }^{2-10}$ Experimental studies showed that mild hypothermia, if rapidly induced before the reperfusion of acute coronary occlusion, can reduce infarct size (IS). ${ }^{11,12}$ So a fast cooling prior to reperfusion may be effective adjunct to primary percutaneous coronary intervention (PCl) in STEMI patients to reduce IS and to improve cardiac outcomes. ${ }^{13,14}$

The development of powerful endovascular cooling systems, which are able to cool down the patient to low temperatures in a few minutes, ${ }^{15}$ brought light for rapid cooling of the patient and its performance in the STEMI scenario. However, there is still concerning regarding a possible delay in the door-to-balloon time (DTB) associated with the implementation of the ETH protocol. Therefore, with the more powerful ETH systems, ${ }^{16}$ the role of cooling as an adjuvant therapy to endovascular cooling in STEMI remains unclear, but delays in ETH certainly would impair the adequate treatment of the patients. 
The aim of the study was the development of a simulation, training \& educational protocol for the multidisciplinary team to perform optimized ETH as an adjunctive therapy for STEMI without delays in DTB which would derail the procedure.

\section{Methods}

\section{Simulation, Training and Debriefing}

Aim: Provide a training program for STEMI Cool trial sites that simulates the procedural flow as described in the trial protocol. This realistic simulation program was created to familiarize site personnel with the procedures required in the protocol and also manage potential complications as listed in the trial protocol that might be related to cooling, while motivating site performance in avoiding delays in the DTB and procedural times consistent for all patients regardless of randomization. All the aspects and a comprehensive description of all the aspects of the simulation intervention are depicted in Table $1 .{ }^{17}$

\section{Realistic simulation performance criteria}

Performance criteria has been established to limit the difference between study arms regarding DTB time to be inferior to 10 minutes. The objective was to quickly perform and complete all procedural steps up to the point where the guide wire is advanced across the lesion. The timing data from the simulation of a patient randomized to the cooling arm was compared to the current average DTB time of the institution, in order to confirm if the difference between study arms regarding DTB time is inferior 10 minutes. Ideally the cases should be performed with a final DTB $<90$ minutes. The workflow overview is shown in Fig. 1.

\section{Keys to success}

A successful realistic simulation program requires the following:

- Assigning roles and responsibilities upfront for each team member;

- Execution of assigned tasks in a timely manner;

- Execution of relevant protocol steps in parallel to reduce total procedural time.

Metrics were assessed regarding each team's performance and reviewed during the debriefing at the end of each simulation.

\section{Training requirements}

The realistic simulation training took place in the Emergency Department, Cath Lab, Intensive Care Unit or Simulated Lab (hereby named Sim Lab) during the Site Initiation Visit (SIV), according to the hospital's allowance.

\section{Timeframe requirements}


1) Expectations and intro: 20 minutes. Prior to the simulation, this was a short recap of the expectations and purpose of the simulation. The study protocol and device training had already taken place earlier in the SIV.

2) Realistic simulation run: 60 minutes. The start point was the patient arrival to the ED. The finish point was the action of the guidewire crossing the lesion during the $\mathrm{PCl}$ procedure.

3) Debriefing: 60 minutes. The debriefing should take place immediately after the simulation was completed.

\section{Patient scenario}

Patient scenarios for use in the simulations were sham mannequins in STEMI situations, from stable to complex cases. For consistency, all the cases were pre-specified, and the initial simulation training conducted at the SIV.

\section{Logistical optimization}

Another focus of simulation and training was the logistical optimization with strategies to reduce waste of time in the patient's transportation from different departments, and avoiding excessive rewarming of the patient during the moving. After several simulations transporting mannequins throughout real sections of the hospital, an appropriate logistic was defined and implemented.

\section{Results}

From July 2015 to January 2016, we successfully developed an optimized simulation protocol using modern mannequins in different realistic scenarios for the treatment of patients undergoing ETH adjunctive to PCI for STEMls starting from the emergency room, through the CathLab, and to the intensive care unit (ICU) using the Proteus ${ }^{\circledR}$ Endovascular System. The comprehensive aspects of the Simulation Intervention are detailed in Table 1, and the workflow overview is shown in Fig. 1.

We successfully trained 361 multidisciplinary professionals in realistic simulation using modern mannequins and sham situations in divisions of the hospital where real patients would be treated. The focus of simulation and training was logistical optimization and educational debriefing with strategies to reduce waste of time in patient's transportation from different departments, and avoiding excessive rewarming of the patient during the moving, as seen in Fig. 2.

\section{Discussion}

In the critical STEMI scenario, where every minute counts to spare viable myocardium cells, it would be hard imagining to perform further time-consuming procedures without impacting in the over-delay for coronary reperfusion. ${ }^{1-10}$ With that said, ETH have never been applied before due to the inherent delay of this procedure, which used to take many hours to cool down the body, therefore it has been incompatible 
with this emergency scenario. The new available advanced technology allowed cooling much faster, with target temperatures as low as $32^{\circ} \mathrm{C}$ being reached in less than 20 minutes. Nevertheless, there was still the problem that even those 20 minutes would impact negatively the coronary reperfusion time, and the revealed solution came from the interaction between conjoined procedures and logistical optimization. This complex equation could only be solved with the application of a high disciplined triad: simulation, training \& education.

Realistic simulation has been an important component of health professionals' training. ${ }^{18-21}$ The caveats of dealing with health in emergent situations do not allow unanticipated mistakes, which would have life-threatening consequences. Advanced cardiac life support (ACLS) courses has long been using realistic simulation as an important tool for teaching and learning, with successful results. ${ }^{22-27}$ We utilized our great experience with this kind of training to come up with realistic scenarios and intensive training before starting the real-world procedures. We started training the multidisciplinary team 2 months prior to the patients' inclusion. Only after our timing targets were reached, we initiated the in-vivo protocol. And at the end of the day, this was the key to the success: recognizing the potential pitfalls and troubles that could emerge during the ETH, solving it, and then by continuous and recurrent training, we were able to overcome a problematic situation and to come up with an optimized protocol.

Simulation, training and debriefing are the triple foundation of the protocol. ${ }^{18-24}$ The first step of the protocol was the realistic simulation. The creation of simulated scenarios using mannequins and predetermined intercurrences during the development of the case brought knowledge and confidence to the multi-professional team. The second step was intensive training, continuous and recurrent, so that there would be no mistakes during the case. The third step was the educational debriefing. After every simulated or real case, the details of the attendance were widely discussed and shared among the multidisciplinary team. Suggestions and corrections we taken into account so that the protocol could be updated and improved over time. Of note, the protocol has a dynamic profile, so it can be reinvented and improved whenever the situation requires it. ${ }^{18-24}$

Current improved technology of the new endovascular Zoll ${ }^{\mathrm{TM}}$ Proteus Cooling System ${ }^{\mathrm{TM}}$ (more powerful than the previous devices) also contributed to the development of a feasible protocol in a timely manner. It is implanted through a simple femoral vein puncture with the introduction of the cooling catheter, which takes few minutes to be performed. On the other hand, it requires 2 different interventionists working at the same time on the patient if the intention is to perform cooling and angiography at the same time, so a dedicated physician is necessary for all cooling procedures.

It is also important to highlight the focusing on logistical optimization for moving the patient among the different departments of the hospital, i.e., from the ER to the Cath Lab, and them to the Coronary Unit. This logistical planning is important not only to avoid any further delays in the DTB, but also to avoid precocious rewarming of the patient during the transportation. Previous trials already have shown the extremely harmful effects of unstable temperature control during temperature target management, so it is utmost to guarantee a stable maintenance of the core temperature. 
Even though randomized clinical trials including COOL MI ${ }^{28}, I C E-I T^{29}, \mathrm{CHILL} \mathrm{MI}^{30}$ and VELOCITY ${ }^{31}$ failed to show a significant reduction in infarct size, endovascular cooling appears to be safe and well tolerated. Despite neutral overall results, subsequent unpublished post hoc subgroup analysis of $\mathrm{COOL} \mathrm{Ml}{ }^{31}$ and ICE-IT, ${ }^{32}$ and combined analysis of RAPID MI-ICE ${ }^{32}$ and CHILL MI ${ }^{30}$ showed significant reduction in infarct size in a subgroup of early presenters with anterior STEMI who were cooled below $35^{\circ} \mathrm{C}$ prior to reperfusion. ${ }^{33}$ Thereby, benefits of therapeutic hypothermia might be achieved by using a rapid cooling to decrease core temperature below $35^{\circ} \mathrm{C}$ prior to the opening of acute coronary occlusion to justify the ETH as an adjunctive therapy in STEMI. ${ }^{33}$

\section{Limitations}

Our results, however, should be interpreted in the light of several limitations. The protocol was singlecenter and therefore easier to get all professionals trained. Secondly, we did not evaluate the learning curve for the professionals, once some of them already had been exposed to ETH procedures. Third, there was no physician exclusively responsible for the cooling procedure, it was performed concomitant to the interventional procedure, which might imply in delays in the DTB. Last, the inherent limitations of mannequin simulators must be taken into account, such as the impossibility of subjective feedback or bleeding events. ${ }^{34}$

\section{Conclusions}

Realistic simulation, intensive training and educational debriefing for the multidisciplinary team propitiated feasible endovascular therapeutic hypothermia as an adjuvant therapy to primary $\mathrm{PCl}$ in STEMI.

\section{Declarations}

\section{Ethics approval and consent to participate}

The COOL-MI InCor Trial was approved by both local (CAPPESQ - number 0242/11) and national (CONEP - approval number 16568) ethical committees. The trial was performed in accordance to the international regulations: 21 CFR Part 812 Investigational Device Exemptions, EN540 Clinical Investigation of Medical Devices For Human Subjects, 21 CFR Part 56 Institutional Review Boards, 21 CFR Part 50 Protection of Human Subjects of United States of America. All the patients were obligated to sign a consent term to be included in the trial.

\section{Consent for publication}

All the authors had approved and had given consent for the publication of this manuscript.

\section{Availability of data and materials}


All data, including published and un-published material will be available upon request.

\section{Competing interests}

Dr. Dae is a consultant for ZOLL Circulation Inc. None of the other authors have conflicts of interest related to this article.

\section{Funding}

This study was financed in part by Zoll Circulation Inc and in part by the Coordenação de Aperfeiçoamento de Pessoal de Nível Superior - Brasil (CAPES) - Finance Code 001.

\section{Authors' contributions}

I contributed substantially in collecting data, as well as data interpretation, analysis, writing and reviewing the manuscript. Dr. Giannetti, Dr. Polastri, Dr. Frossard Lima, Dr. San Martin, Dr. Rochitte, Dr. Hajjar, Dr. Gallego Lima, Dr. Nicolau, Dr. Oliveira Jr, Dr. Dallan, Dr. Dae, Dr Ribeiro da Silva and Dr. Kalil Filho contributed substantially in the analysis and interpretation of data. Dr Lemos Neto and Dr. Timerman are the co-senior authors of this manuscript and had access to all the data, contributed in data interpretation, and reviewing the manuscript for important intellectual content.

\section{Acknowledgements}

We thank all the crew from the emergency department and intensive care unit for their efforts on simulation and training that ultimately culminated with the amazing results hereby published.

\section{References}

1. Yellon DM, Hausenloy DJ. Myocardial reperfusion injury. N Engl J Med. 2007;357(11):1121-35.

2. Piegas LS, Timerman A, Feitosa GS, Nicolau JC, Mattos LAP, Andrade MD, Avezum A, Feldman A, De Carvalho ACC, Sousa ACS, Mansur AP, Bozza AEZ, Falcão BAA, Markman Filho B, Polanczyk CA, Gun C, Serrano Junior CV, Oliveira CC, Moreira D, Précoma DB, Magnoni D, Albuquerque DC, Romano ER, Stefanini E, Santos ES, God EMG, Ribeiro EE, Brito Júnior FS, Feitosa-Filho GS, Arruda GDS, Oliveira GBF, Oliveira GBF, Lima GG, Dohmann HFR, Liguori IM, Costa JR, Saraiva JFK, Maia LN, Moreira LFP, Arrais M, Canesin MF, Coutinho MSSA, Moretti MA, Ghorayeb N, Vieira NW, Dutra OP, Coelho OR, Leães PE, Rossi PRF, Andrade PB, Lemos PA, Pavanello R, Vivacqua Costa RC, Bassan R, Esporcatte R, Miranda R, Giraldez RRCV, Ramos RF, Martins SK, Esteves VBC. Mathias Junior W. V Diretriz da Sociedade Brasileira de Cardiologia sobre Tratamento do Infarto Agudo do Miocárdio com Supradesnível do Segmento ST. Arq Bras Cardiol. 2015;105(2):1-105.

3. Bernoche Claudia T, Sergio PT, Facholi GN, Schiavo, Siqueira Adailson Wagner da Silva, Piscopo Agnaldo et al. Atualização da Diretriz de Ressuscitação Cardiopulmonar e Cuidados Cardiovasculares de Emergência da Sociedade Brasileira de Cardiologia - 2019. Arq. Bras. Cardiol. 
[Internet]. 2019 Sep [cited 2020 July 25]; 113(3): 449-663.Available

from:http://www.scielo.br/scielo.php?script=sci_arttext\&pid=S0066-782X2019000900449\&lng=en.

Epub Oct 10, 2019. https://doi.org/10.5935/abc.20190203.Neumar RW, Nolan JP, Adrie C, Aibiki M, Berg RA.

4. Bottiger BW, et al. Post-cardiac arrest syndrome: epidemiology, pathophysiology, treatment, and prognostication. A consensus statement from the International Liaison Committee on Resuscitation (American Heart Association, Australian and New Zealand Council on Resuscitation, European Resuscitation Council, Heart and Stroke Foundation of Canada, InterAmerican Heart Foundation, Resuscitation Council of Asia, and the Resuscitation Council of Southern Africa); the American Heart Association Emergency Cardiovascular Care Committee; the Council on Cardiovascular Surgery and Anesthesia; the Council on Cardiopulmonary, Perioperative, and Critical Care; the Council on Clinical Cardiology; and the Stroke Council. Circulation. 2008;118(23):2452-83.

5. Neumar RW, Shuster M, Callaway CW, et al. Part 1: executive summary: 2015 American Heart Association Guidelines Update for Cardiopulmonary Resuscitation and Emergency Cardiovascular Care. Circulation. 2015;132(suppl 2):315-67.

6. Nolan JP, Hazinski MF, Aicken R, Bhanji F, Billi JE, Callaway CW, Castren M, de Caen AR, Ferrer JME, Finn JC, Gent LM, Griffin RE, Iverson S, Lang E, Lim SH, Maconochie IK, Montgomery WH, Morley PT, Nadkarni VM, Neumar RW, Nikolaou NI, Perkins GD, Perlman JM, Singletary EM, Soar J, Travers AH, Welsford M, Wyllie J, Zideman DA. Part 1: executive summary: 2015 International Consensus on Cardiopulmonary Resuscitation and Emergency Cardiovascular Care Science With Treatment Recommendations. Resuscitation. 2015;95:e1-32.

7. O'Gara PT, Kushner FG, Ascheim DD, et al. 2013 ACCF/AHA guideline for the management of STelevation myocardial infarction. A report of the American College of Cardiology Foundation/American Heart Association Task Force on Practice Guidelines. Circulation. 2013;127:e362-425.

8. Levine GN, O'Gara PT, Bates ER, et al. 2015 ACC/AHA/SCAl Focused Update on Primary Percutaneous Coronary Intervention for Patients With ST-Elevation Myocardial Infarction: an Update of the 2011 ACCF/AHA/SCAI Guideline for Percutaneous Coronary Intervention and the 2013 ACCF/AHA Guideline for the Management of ST-Elevation Myocardial Infarction: a Report of the American College of Cardiology/American Heart Association Task Force on Clinical Practice Guidelines and the Society for Cardiovascular Angiography and Interventions. J Am Coll Cardiol. 2015. doi:10.1016/j.jacc.2015.10.005.

9. Koenraad G, Monsieurs JP, Nolan, et al. European Resuscitation Council Guidelines for Resuscitation 2015. Resuscitation. 2015;95:1-80.

10. Dallan LAP, Giannetti NS, Rochitte CE, Polastri TF, Bernoche San Martin CY, Hajjar LA, Lima FG, Nicolau JC, Oliveira Mt, Jr, Dae M, Ribeiro da Silva EE, Kalil Filho R, Lemos Neto PA and Timerman S. Cooling as an Adjunctive Therapy to Percutaneous Intervention in Acute Myocardial Infarction: COOL-MI InCor Trial. Ther Hypothermia Temp Manag. 2020. 
11. Duncker DJ, Klassen CL, Ishibashi Y, Herrlinger SH, Pavek TJ, Bache RJ. Effect of temperature on myocardial infarction in swine. Am J Physiol. 1996;270(4 Pt 2):H1189-99.

12. Dae MW, Gao DW, Sessler DI, Chair K, Stillson CA. Effect of endovascular cooling on myocardial temperature, infarct size, and cardiac output in human-sized pigs. Am J Physiol Heart Circ Physiol. 2002;282:H1584-91.

13. Erlinge D. A Review of Mild Hypothermia as an Adjunctive Treatment for ST-Elevation Myocardial Infarction. Ther Hypothermia Temp Manag. 2011;1:129-41.

14. Hausenloy DJ, Yellon DM. Myocardial ischemia-reperfusion injury: a neglected therapeutic target. J Clin Invest. 2013;123:92-101.

15. Noc M, Erlinge D, Neskovic A, Kafedzic S, Merkely B, Zima E, Fister M, Petrovic M, Cankovic M, Veress G, Laanmets P, Pern T, Vukcevic V, Dedovic V, Sredniawa B, Swiatkowski A, Keeble TR, Davies JR, Warenits AM, Olivecroma G, Peruga JZ, Ciszewski M, Horvath I, Edes I, Nagy GG, Aradi D, Holzer M. COOL AMI EU Pilot Trial: a multicentre, prospective, randomized controlled trial to assess cooling as an adjunctive therapy to percutaneous intervention in patients with acute myocardial infarction. Eurointervention. 2017;13:1-9.

16. Willms JF, Boss O, Keller E. Safety, Feasibility, and Efficiency of a New Cooling Device Using Intravenous Cold Infusions for Fever Control. Neurocrit Care. 2019;30(1):149-56.

17. Cheng A, Kessler D, Mackinnon R, et al. Reporting guidelines for health care simulation research: extensions to the CONSORT and STROBE statements. Adv Simul (Lond). 2016;1:25.

18. Electronic randomization website. Sealed Envelope. Available in: http://www.sealedenvelope.com.

19. Endacott R, Gale T, O'Connor A, et al. Frameworks and quality measures used for debriefing in teambased simulation: a systematic review. BMJ Simulation Technology Enhanced Learning. 2019;5:6172.

20. Fanning RM, Gaba DM. The role of debriefing in simulation-based learning. Simul Healthc. 2007;2:115-25.

21. Cooper JB, Taqueti VR. A brief history of the development of manikin simulators for clinical education and training. Qual Saf Health Care. 2004;13(Suppl 1):i11-8.

22. Delasobera B, Goodwin T, Strehlow M, Gilbert G, D'Souza P, Alok A, Raje P, Mahadevan S. November 18). Evaluating the efficacy of simulators and multimedia for refreshing ACLS skills in India. Resuscitation 2010 Feb. 2009;81(2):217-23.

23. Davis L, Storjohann T, Spiegel J, Beiber K, Barletta J. (2013, April 12). High-fidelity simulation for advanced cardiac life support training. Am J Pharm Educ. Apr 12 2013;77(3):59.

24. Wayne D, Didwania A, Feinglass J, Fudala M, Barsuk J, McGaghie W. (2007, June 15). Simulationbased education improves quality of care during cardiac arrest team responses at an academic teaching hospital: a case-control study. Chest 2008 Jan; Vol. 133 (1), pp. 56-61.

25. Rodgers DL, Securro S Jr, Pauley RD. The effect of high-fidelity simulation on educational outcomes in an advanced cardiovascular life support course. Simul Healthc. 2009;4(4):200-6. 
26. Hoadley TA. Learning advanced cardiac life support: a comparison study of the effects of low- and high-fidelity simulation. Nurs Educ Perspect. 2009;30(2):91-5.

27. DeMaria S, Silverman R, Lapidus K, Williams C, Spivack J, Levine A, Goldberg A. (2016, April 7). The impact of simulated patient death on medical students' stress response and learning of ACLS. The impact of simulated patient death on medical students' stress response and learning of ACLS. Medical Teacher 2016 Jul; Vol. 38 (7), pp. 730-7.

28. Dixon SR, Whitbourn RJ, Dae MW, Grube E, Sherman W, Schaer GL, Jenkins JS, Baim DS, Gibbons RJ, Kuntz RE, Pompa JJ, Nguyen TT, O'Neill WW. Induction of mild systemic hypothermia with endovascular cooling during primary percutaneous coronary intervention for acute myocardial infarction - COOL MI Trial. J Am Coll Cardiol. 2002;40:1928-34.

29. O’Neill WW, Dixon SR, Grines CL. The year in interventional cardiology. J Am Coll Cardiol. 2005;45:1117-34.

30. Erlinge D, Götberg M, Lang I, Holzer M, Noc M, Clemmensen P, Jensen U, Metzler B, James S, Bötker HE, Omerovic E, Engblom H, Carlsson M, Arheden H, Ostlund O, Wallentin L, Harnek J, Olivecrona GK. Rapid endovascular catheter core cooling combined with cold saline as an adjunct to percutaneous coronary intervention for the treatment of acute myocardial infarction. The CHILL-MI trial: a randomized controlled study of the use of central venous catheter core cooling combined with cold saline as an adjunct to percutaneous coronary intervention for the treatment of acute myocardial infarction. J Am Coll Cardiol. 2014;63:1857-65.

31. Nichol G, Strickland W, Shavelle D, Maehara A, Ben-Yehuda O, Genereux P, Dressler O, Parvataneni R, Nichols M, McPherson J, Barbeau G, Laddu A, Elrod JA, Tully GW, Ivanhoe R, Stone GW. VELOCITY Investigators. Prospective, multicenter, randomized controlled pilot trial of peritoneal hypothermia in patients with ST-segment-elevation myocardial infarction. Circ Cardiovasc Interv. 2015;8:e001965.

32. Götberg M, Olivecrona GK, Koul S, Carlsson M, Engblom H, Ugander M, van der Pals J, Algotsson L, Hakan A, Erlinge D. A pilot study of rapid cooling by cold saline and endovascular cooling before reperfusion in patients with ST-elevation myocardial infarction - RAPID-MI ICE Trial. Circ Cardiovasc Interv. 2010;3:400-7.

33. Erlinge D, Götberg M, Noc M, Lang I, Holzer M, Clemmensen P, Jensen U, Metzler B, James S, Botker HE, Omerovic E, Koul S, Engblom H, Carlsson M, Arheden H, Östlund O, Wallentin L, Klos B, Harnek J, Olivecrona GK. Therapeutic hypothermia for the treatment of acute myocardial infarction-combined analysis of the RAPID MI-ICE and the CHILL-MI trials. Ther Hypothermia Temp Manag. 2015;5:7784.

34. Dreifuerst KT. Using debriefing for meaningful learning to foster development of clinical reasoning in simulation. J Nurs Educ. 2012;51:326-33.

\section{Tables}


Table 1

Comprehensive aspects of the Simulation Intervention

\begin{tabular}{|c|c|c|}
\hline Elements & Subelements & Description \\
\hline \multirow[t]{2}{*}{$\begin{array}{l}\text { Participant } \\
\text { orientation }\end{array}$} & $\begin{array}{l}\text { Orientation to the } \\
\text { simulator }\end{array}$ & $\begin{array}{l}\text { Expectations and intro: } 20 \text { minutes. Prior to the simulation, } \\
\text { this was a short recap of the } \\
\text { expectations and purpose of the simulation, as well as the } \\
\text { study protocol. All the professionals must had been trained } \\
\text { in Advanced Life Care Support (ACLS) in the Simulation } \\
\text { Center prior to the TH simulation. } \\
\text { Realistic simulation run: } 60 \text { minutes. The start point was } \\
\text { the patient arrival to the ED. The } \\
\text { finish point was the action of the guidewire crossing the } \\
\text { lesion during the PCl procedure. } \\
\text { Debriefing: } 60 \text { minutes. The debriefing should take place } \\
\text { immediately after the simulation } \\
\text { was completed. }\end{array}$ \\
\hline & $\begin{array}{l}\text { Orientation to the } \\
\text { environment }\end{array}$ & $\begin{array}{l}\text { The participants were oriented to the environment } \\
\text { according to the proposed HT procedure. There was a real } \\
\text { body-size mannequin that was used both to do the TH } \\
\text { procedure and to be transferred from one unit to the other } \\
\text { according to the timeline of the simulation. The } \\
\text { professionals being trained were trained in different } \\
\text { sections of the hospital. Therefore, they started at the } \\
\text { Emergency Department (ED), then went to the cath lab and } \\
\text { finished at the intensive care unit (ICU). } 15 \text { minutes for } \\
\text { orientation, } 30 \text { minutes for each section (ED, cath lab, ICU) } \\
\text { and } 15 \text { minutes for conclusion, for a total of } 2 \text { hours } \\
\text { training. The content for the training was specific for each } \\
\text { of the scenarios. }\end{array}$ \\
\hline \multirow[t]{2}{*}{$\begin{array}{l}\text { Simulator } \\
\text { type }\end{array}$} & $\begin{array}{l}\text { Simulator make and } \\
\text { model }\end{array}$ & $\begin{array}{l}\text { The training was performed using the original Proteus } \\
\text { Cooling System (Zoll Circulation Inc) with sham } \\
\text { temperature targets. }\end{array}$ \\
\hline & Simulator functionality & $\begin{array}{l}\text { The simulator was the real Proteus device with } \\
\text { connections to a software that mimicked the temperature } \\
\text { of the patient for each time point. It was possible to } \\
\text { determine specific temperatures according to the scenario. } \\
\text { The limitations were the same inherent to any simulator, } \\
\text { i.e., no human being was involved as part of the simulator, } \\
\text { only mannequins, so there was no feedback regarding } \\
\text { bleedings or subjective feelings. Arrhythmias were } \\
\text { simulated using monitors and defibrillators. }\end{array}$ \\
\hline \multirow[t]{2}{*}{$\begin{array}{l}\text { Simulation } \\
\text { environment }\end{array}$} & Location & $\begin{array}{l}\text { The simulation was conducted in situ clinical environment. } \\
\text { Therefore, they started at the Emergency department, then } \\
\text { went to the cath lab and finished at the intensive care unit } \\
\text { (ICU). }\end{array}$ \\
\hline & Equipment & $\begin{array}{l}\text { It was used one of the } 3 \text { original Proteus Cooling } \\
\text { Systems }{ }^{T M} \text { (Zoll Circulation } \operatorname{lnc}^{T M} \text { ) available at the hospital, } \\
\text { each of them located at the ED, cath lab and ICU. Also, } \\
\text { there were real defibrillators available in each of the units. }\end{array}$ \\
\hline
\end{tabular}




Elements Subelements Description

External stimuli

There were external stimuli such as background noise in all the units. We secured that the simulation training did not interfere in real clinical practice in each of the units, once the simulations were performed in the real units of the hospital.

Simulation Event description event/ scenario
All the scenarios were previously programmed and scripted, and they would change according to the training's reactions. All scenarios were STEMI patients with meet inclusion and exclusion criteria's that would have had been included in the trial and therefore required $\mathrm{TH}$. They all followed the consistent pathway and progression of the $\mathrm{TH}$ across the different units were they were performed.

Learning objectives
- Assigning roles and responsibilities upfront for each team member;

- Execution of assigned tasks in a timely manner;

- Execution of relevant protocol steps in parallel to reduce total procedural time.
Group vs. individual practice

Use of adjuncts

Facilitator/ operator characteristics

Pilot testing
The simulation was conducted in groups, once the $\mathrm{TH}$ is a multidisciplinary procedure.

No other adjuncts were used.

All the facilitators were from the multidisciplinary team involved directly and responsible for the therapeutic hypothermia procedure. They were all high-skill experienced health care professionals.

A total of 5 pilot testing's with 2-hour duration were conducted one month prior to the full training of the team, so that pitfalls could be corrected and optimizations could be implemented.

Actors/ standardized/ simulated patients
All the simulations were performed in mannequins. There were no actors involved. All the scenarios were conducted by experienced clinicians with experience in simulator education.
Instructional Duration

design
The total duration of each simulation was 140 minutes.

Timing

The simulation should be performed prior to the initiation of the clinical trial. All the professionals involved in the TH procedure should be trained.

Frequency/ repetitions
There was only one formal training / simulation per professional, but there would be the possibility of retraining if the clinical team considered necessary to repeat the process for quality enhancement.

Clinical variation
A unique template script was used for the training once all the situations involved the same scenario: a STEMI patient that should undergo therapeutic hypothermia concomitant to the percutaneous coronary intervention 


Elements Subelements Description

Standards/assessment As a multi-disciplinary team, all the professionals were assessed at the end of the debriefing to understand if they had assimilated the concepts and if they were able to apply it in the clinical practice, but there was no formal testing at the end of the simulation.

Adaptability of intervention

Range of difficulty

All the simulations were performed in groups, but with individual learning focus on the role of each multidisciplinary professional in the TH procedure.

Therapeutic hypothermia is a very complex procedure, therefore all the scenarios were focused on a critical situation involving STEMI and primary $\mathrm{PCl}$ concomitant to the $\mathrm{TH}$.

Nonsimulation interventions and adjuncts

As for the nonsimulation interventions, a debriefing should take place immediately after the simulation was completed, and was performed in small group discussions.

Integration

The intervention was integrated into curriculum as part of the armamentarium for all the multidisciplinary team in our facility, as a new skill for all the different professionals.

Feedback and/ or debriefing
Source

Duration

Facilitator presence

Facilitator characteristics

Content

Structure/method
The feedback was performed using the simulator itself, the computer through a didactic approach from the facilitator.

The total duration of each simulation was 140 minutes.

At least one high-skilled experienced facilitator was present in all the simulations.

All the facilitators were from the multidisciplinary team involved directly and responsible for the therapeutic hypothermia procedure. They were all high-skill experienced health care professionals.

The simulation focused on teamwork and development of clinical skills in all the aspects of therapeutic hypothermia.

The debriefing was performed using the simulator itself, the computer through a didactic approach from the facilitator. The whole simulation was revised, all the possible diversions were corrected and all the clarifications and questions were solved.

Timing

The feedback was conducted both concurrent to the simulation event, with guidance and orientation when necessary, as well as an extensive debriefing at the end of the simulation.

Video
Video could be recorded during the simulation to help in the education feedback when necessary, especially during the final debriefing when appropriate, but it was not compulsory to record all the simulation events. 


\begin{tabular}{|c|c|c|}
\hline Elements & Subelements & Description \\
\hline & Scripting & $\begin{array}{l}\text { A unique template script was used for the training once all } \\
\text { the situations involved the same scenario: a STEMI patient } \\
\text { that should undergo therapeutic hypothermia concomitant } \\
\text { to the percutaneous coronary intervention. }\end{array}$ \\
\hline
\end{tabular}

\section{Figures}

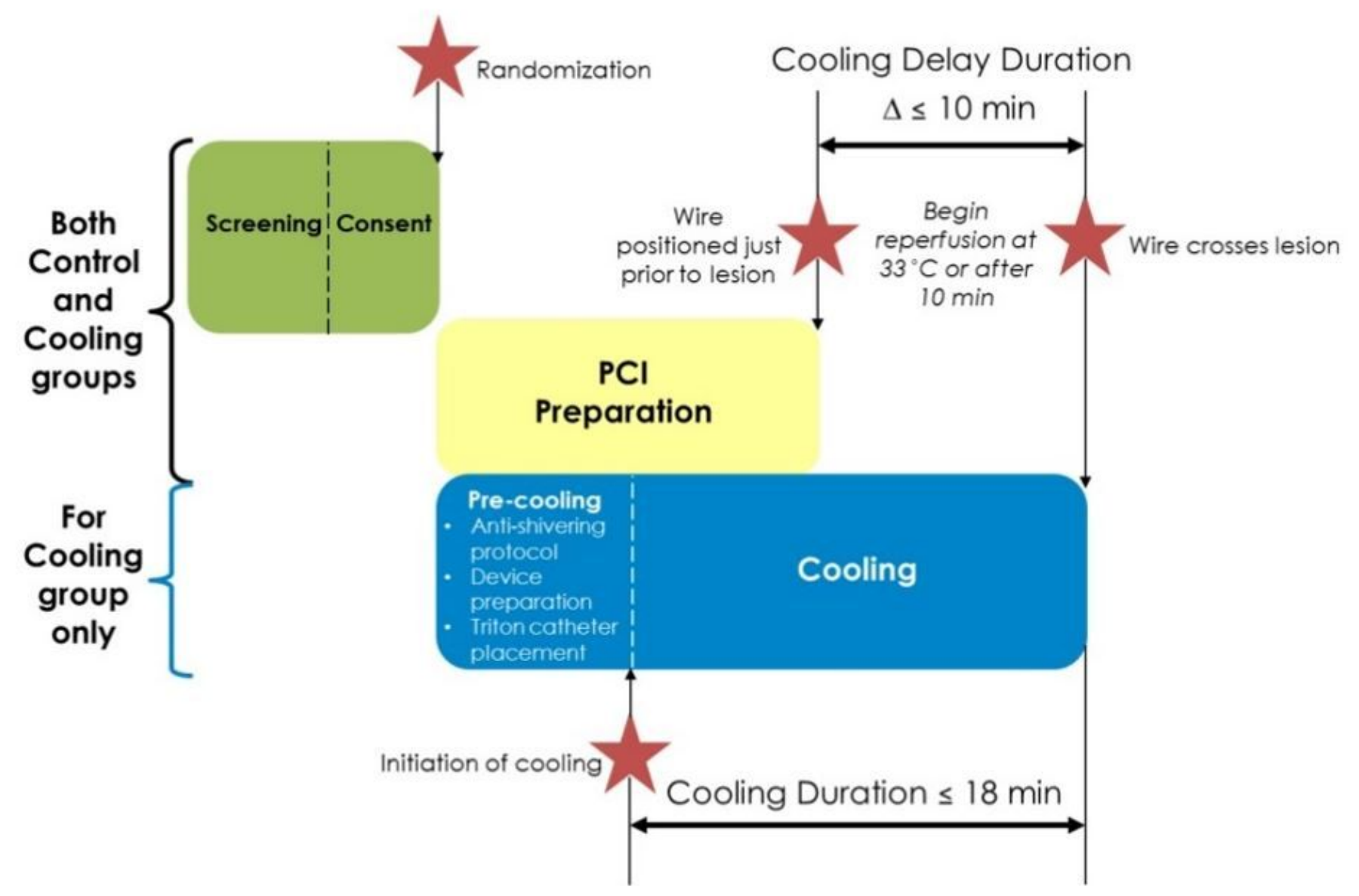

\section{Figure 1}

Realistic simulation workflow overview. The green bar is the time needed for screening and enrollment tasks required to conduct any trial in the STEMI population (enrollment steps). The yellow bar ( $\mathrm{PCl}$ preparation) represents the routine steps for performing percutaneous coronary intervention (PCl) for the STEMI population. Both Green and Yellow steps were required in both the control and cooling groups. The blue bar (cooling steps) represents the additional steps that are required in the cooling group. Since some but not all of the cooling steps are conducted in parallel to others, the difference in DTB time between the control and cooling groups is expected to be inferior than 10 minutes. 

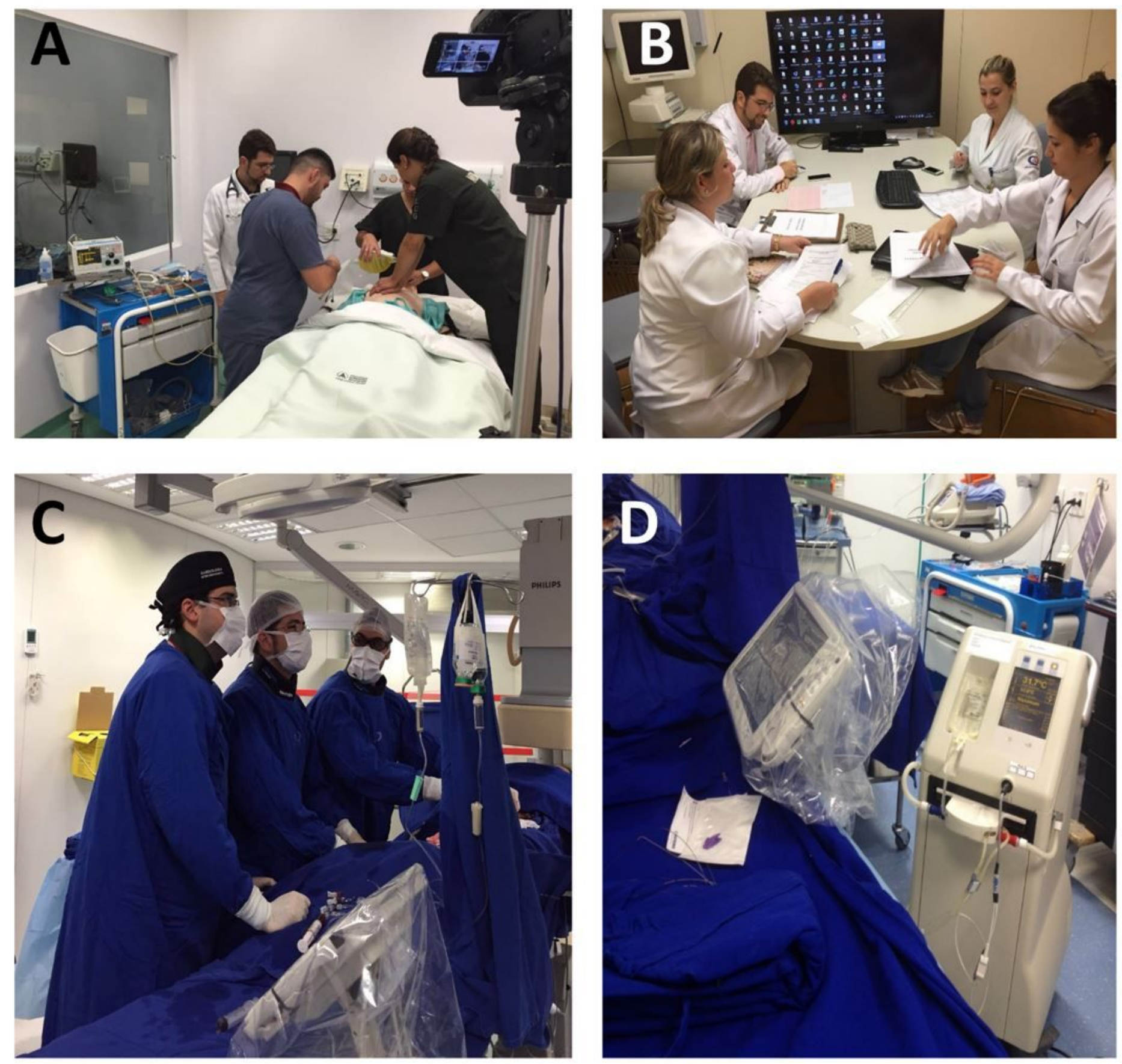

\section{Figure 2}

Pictures of the multidisciplinary team being trained in the Simulation Laboratory (Sim Lab) and real procedure in the catheterization laboratory (Cath Lab). Panel A: Realistic simulation. Panel B: Educational

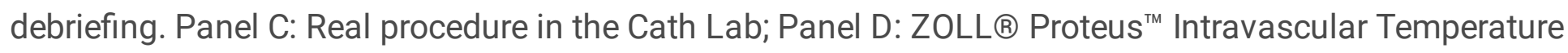
Management System ${ }^{\text {TM }}$ device in detail. 


\section{Image not available with this version}

Figure 3

Temperature over time in hypothermia and control groups from baseline to rewarming.

\section{Image not available with this version}

Figure 4

Example of a cooling curve using endovascular hypothermia.

\section{Image not available with this version}

Figure 5 
Comparison of door-to-balloon times between the hypothermia group and the control group in the AsTreated (ATT) analysis. Of note, the 5.1 minutes difference was not statistically significant. 